\title{
Depression among Older Adult Prisoners at the Jos Central Prison- North Central Nigeria
}

\author{
Piwuna $\mathrm{CG}^{1 *}$, Piwuna $\mathrm{TO}^{2}$, Dami ${ }^{3}$, Bankat $\mathrm{MA}^{1}$, Agbir TM${ }^{1}$, Nwoga $\mathrm{CN} .{ }^{1}$ \\ ${ }^{\prime}$ Department of Psychiatry, College of Health Sciences University of Jos \\ ${ }^{2}$ Department of Hematology, College of Health Sciences, University of Jos \\ ${ }^{3}$ Department of Community Medicine, College of Health Sciences, University of Jos \\ *Corresponding Author: Dr. Piwuna CG. Department of Psychiatry, College of Health Sciences \\ University of Jos Email:piwuna01@gmail.com
}

\begin{abstract}
This study was carried out to determine the prevalence of depression and its correlates among Older Adult Prisoners at the Jos Central Prison, North Central Nigeria. The study was a cross-sectional descriptive chart, conducted at the Jos Central prisons on eighty-six (86) older prisoners between June 2012 to December 2012. Bio-demographic data and history of any chronic medical condition as well as that of psychiatric condition were also obtained from their clinical records in the clinic located within the prison. Depression was assessed using the Geriatric Depression Scale (GDS) on all the volunteers 50 years and above. The GDS measures cognitive, affective, functional state and a factor that reflects helplessness and fear for the future. The study was largely composed of male making up to $99 \%$. The age range was between 50 to 75 years with a mean 54.36 (SD 3.24) with most of them between 50 to 60 years (90\%). A quarter (25\%) had not received any form of education while 7 out of 10 had received some form of education. Majority of them were employed (skilled or un-skilled employment) before incarceration. Only $2 \%$ were unemployed before their incarceration. Those incarcerated for violent crimes (65\%) nearly doubled those in prison for non-violent crimes 35\%. Occupational status, pre-existing medical conditions and the perception of their health status before incarceration were found to be statistically significant. Type of crimes committed was not statistically significant. Known chronic medical condition(s) was a risk factor in the inmates developing depression (P-value $=0.009)$. In comparing the specific medical conditions with depression, significant findings were found ( $\mathrm{P}-\mathrm{value}=0.003)$. The study revealed a prevalence of depression at $59 \%$ in older prisoners of 50 years and above. The significant predictors of depression include occupational status, pre-exisitng medical conditions, and the perception of their health status before incarceration were found to be statistically significant.
\end{abstract}

Keywords: Depression, Prevalence, Older adults

\section{INTRODUCTION}

P sychiatric disorders are known to be common among prisoners than in the general population ${ }^{1}$. This is understandably so, because prison life can be very stressful with the potentials to exacerbate pre-existing psychiatric disorders and "bring forward "disorders in the vulnerable. Varying definitions of older prisoners have emerged over the years. This includes those over 45, 50, 60 and 65 years. It is so because prisoners tend to undergo "accelerated ageing due to health and lifestyle factors that occur before and during imprisonment. ${ }^{2}$ However, disorders in the older prisoners have not been as commonly studied as among general prison population. 
Physical and functional health decline among older prisoners give rise to a lot of difficulties in environments that are not originally designed for young and able-bodied people ${ }^{3}$. Of the over 10 million prisoners in the world, over $50 \%$ are in the Western developed nations including Russia and China ${ }^{4}$. While progress is being made towards access to justice for those behind bars, there is a crucial need to boost capacity of health care delivery in prisons, especially for older adults.

Currently in Nigeria, there is no operative national policy for the care of older adults, not to talk of older prisoners. Because of the different kind of health needs and comorbidities of older prisoners and the fact that the prisons are not built for older persons but for the young and strong individuals, the cost and provision of health care for older prisoners is usually ignored and underestimated. Concerning their mental health, factors such as bullying and intimidation, physical demands of prison life ${ }^{5,}$ as well as a phenomenon known as "Institutional thoughtlessness" " , have been put forward as the reasons why older prisoners are prone to depression and other mental health illnesses. Variables that were considered in this study that might have contributed to depression among this older prison population include type of crime committed (violent or non-violent), co-existing chronic medical condition, and duration of stay in prison and perception of their state of health. History of psychiatric illness and whether the prisoner has been reviewed by a psychiatrist in the past or while in prison was equally assessed in relation to depression.

Indeed the prison is society's way of inflicting pain in an individual for breaking society's law and offending a community $^{7}$. However, while in prison, ill-health and health inequalities do exist and explained by social conditions within the prison environment and across the life course. This social model of health combines a prisoners subjective experiences and his perception of ill health ${ }^{8}$.

This study represents an attempt to add to the scarce body of knowledge about older prisoners in Nigeria and factors that may predict depression among them.

\section{MATERIALS AND METHODS}

\section{StudyArea}

The study was a cross-sectional descriptive chart, conducted at the Jos Central prisons on eighty-six (86) older prisoners (those over 50 years) between June 2012 to December 2012. Informed consent was sought and freely given in the absence of prison officials to ensure confidentiality and to avoid coercion. The prisoners were further assured that the information given will not be used for anything other than the study.

Bio demographic data like age, gender, marital status and education were obtained from those who participated in the study. Information on history of any chronic medical condition as well as any history of psychiatric condition was also obtained from their clinical records in the clinic located within the prison.

Depression was assessed using the Geriatric Depression Scale (GDS) on all the volunteers over the age of 50. Every question on the GDS has two (2) possible responses. Each bold print had a score of one (1) and the other normal print had a score of zero (0). The total score of fifteen (15) can be obtained when all the score per respondent is added. The GDS measures cognitive, affective, functional state and a factor that reflects helplessness and fear for the future ${ }^{9}$

SPSS version 2.0 was used for data analysis. Prevalence of depression in the sample was calculated, the student t-test and chi-square were used to test for significance and a logistic regression also calculated. P-value was set at $<0.05$. Ethical clearance was obtained for the study from the Prison authorities and the rights of the inmates to participate or discontinue at any time was respected.

\section{RESULTS}

The sample was overwhelmingly male $99 \%$, with only a percentage of female who was over 50 years of age (table 1). The prisoners were categorized into three (3), based on their age with over $90 \%$ within the age group of 50-60 years. Almost three quarters (68\%) were married, $15 \%$ single and $10 \%$ were divorced. A quarter $(25 \%)$ had not received any form of education while almost $75 \%$ had received some form of education. Majority of them were employed (skilled or unskilled employment) before incarceration. Only $2 \%$ were unemployed before their incarceration. Those incarcerated for violent crimes $(65 \%)$ nearly doubled those in prison for non-violent crimes $35 \%$.

About half (53\%) had been incarcerated for between 1-5 years, with only a few serving over 20 years (Fig I)

Expectedly (Fig II), older prisoners with chronic medical conditions which include Hypertension, Diabetes, Memory deficits, and Arthritis and other Comorbid medical conditions made up $68 \%$ doubling those with no medical conditions (31\%). Only $33 \%$ (28) of the sample failed to meet the 
diagnosis of depression, while $67 \%$ had significant score to warrant the diagnosis of depression that would lead to treatment (Tab 3).

While comparing different variables (Table 4), age, education, marital status and gender did not yield any statistical significance. However, occupational status, pre existing medical conditions and the perception of their health status before incarceration were found to be statistically significant. Type of crimes committed was also not found to be of any statistical significance. Known chronic medical conditions were statistically significant as a risk in the inmates developing depression with a $p=0.009$. In comparing the specific medical conditions with depression, significant findings were found $p$-value of 0.003 .

Table I: Baseline Characteristics of Participants among Older Prisoners at Jos Central Prison

\begin{tabular}{llcl}
\hline Characteristics & Frequency & (n=86) & Percentage \\
\hline Gender & Male & 85 & $98.84 \%$ \\
Age & Female & 1 & $1.16 \%$ \\
& $50-60$ & 71 & $93.02 \%$ \\
\multirow{5}{*}{ Marital Status } & $61-70$ & 5 & $5.82 \%$ \\
& $>70$ years & 1 & $1.16 \%$ \\
& Single & 13 & $15.12 \%$ \\
& Divorced & 9 & $10.47 \%$ \\
Education & Separated & 2 & $2.33 \%$ \\
& Married & 59 & $68.60 \%$ \\
& Widow & 3 & $3.49 \%$ \\
Religion & No Education & 20 & $23.26 \%$ \\
& Pri./Sec. & 58 & $67.46 \%$ \\
& Tertiary & 6 & $6.98 \%$ \\
& Drop-out & 2 & $2.33 \%$ \\
Occupation & Islam & 31 & $36.05 \%$ \\
& Christian & 54 & $62.79 \%$ \\
Residence & Others & 1 & $1.16 \%$ \\
& Unemployed & 2 & $2.33 \%$ \\
& Employed & 84 & $97.67 \%$ \\
& Urban & 46 & $53.49 \%$ \\
& Sub-Urban & 12 & $13.95 \%$ \\
& Rural & 28 & $32.56 \%$ \\
& Violent & 56 & 65.12 \\
& Non-Violent & 30 & 34.88 \\
\hline \multirow{5}{*}{ Offence } & & &
\end{tabular}

Those incarcerated for violent crimes nearly double $(65 \%)$ that of those in prison for non-violent crimes $35 \%$.

About half 53\%, had been incarcerated for between 1-5 years, while those serving over 20 years in prison consists only $3.49 \%$ (Fig I).

On the health status of the patients, considerably large percentage were incarcerated with known medical conditions $68.10 \%$, those with a history of Psychiatric illness were $11.63 \%$ and almost half $46.51 \%$ perceived their health state as poor (Tab. 2).

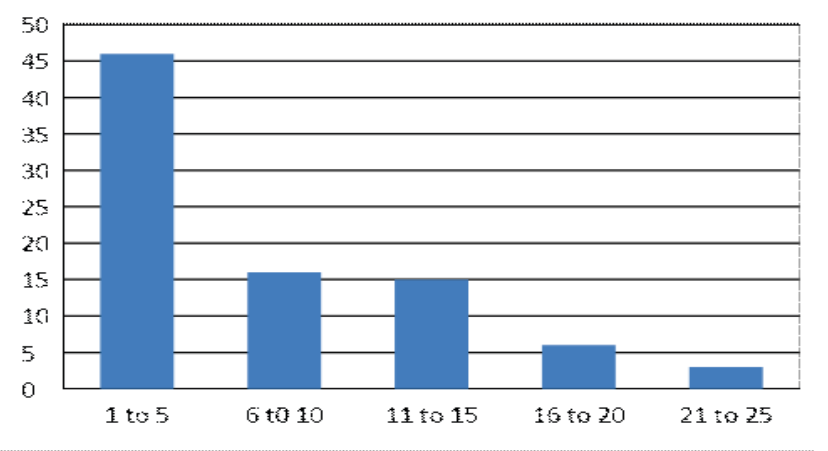

Figure 1: Duration of Stay in the hospital

Table 2: Health Status of Participants

\begin{tabular}{lllll}
\hline Status & \multicolumn{2}{l}{ Frequency $(\mathrm{n}=86)$} & & Percentage (100\%) \\
& & & & \\
\hline Those with known medical conditions & Yes & - & 59 & $68.60 \%$ \\
& No & - & 27 & $31.40 \%$ \\
Those who have psychiatric illness & Yes & - & 10 & $11.63 \%$ \\
& No & - & 76 & $88.37 \%$ \\
How do you assess your health & V. Good & - & 6 & $6.98 \%$ \\
& Good & - & 40 & $46.51 \%$ \\
& Poor & - & 40 & $46.51 \%$ \\
\hline
\end{tabular}

As shown in Fig II, older prisoners with chronic medical conditions which included hypertension, diabetes, memory deficits, arthritis and comorbid medical conditions $(68 \%)$ doubled those with no medical conditions.

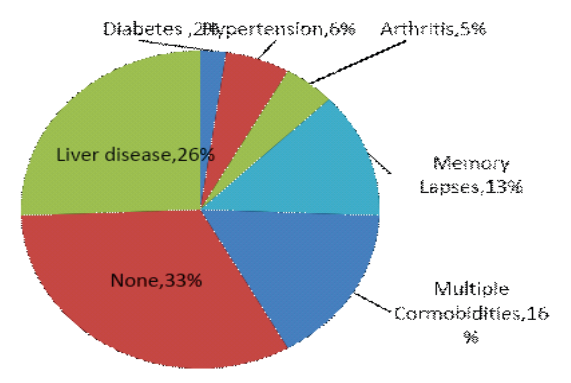

Fig II: Pie chart depicting individuals with known medical conditions.

Table 3: Scores of participants on Geriatric Depression Scale (GDS)

\begin{tabular}{lll}
\hline Score & Frequency & Percentage \\
\hline $0-9$ & 28 & 32.56 \\
$10-19$ & 32 & 37.21 \\
$20-31$ & 26 & 30.23 \\
\hline
\end{tabular}


Based on the cut off score of 10 and above as significant, only $33 \%$ of the sample failed to meet the diagnosis of depression, while $67 \%$ had significant score to warrant the diagnosis of depression that could even warrant treatment (Table 3). Using bivariate analysis of age, education, marital status and gender against their scores on the depression scale did not yield any statistical significance. However, occupational status before incarceration was found to be statistically significant $\mathrm{p}$-value $=0.03$ (Table 4) ie occupation and depression. Type of offence committed was also not found to be of any statistical significance. Known chronic medical conditions were statistically significant as a risk for developing depression with a value of 0.009 .

Table 4: Cross tabulation of factors associated with depression among older Prisoners in Jos Central Prison

\begin{tabular}{ll}
\hline Characteristics & P-Value \\
\hline Occupation/Depression & 0.0355 \\
Religion/Depression & 0.0689 \\
Education/Depression & 0.0801 \\
Marital Status/Depression & 0.3023 \\
Age/Depression & \\
Gender/Depression & 0.5079 \\
Residence/Depression & 0.1705 \\
Offence/Depression & 0.4504 \\
Known Medical Condition/Depression & 0.0090 \\
History of Psych/Depression & 0.4744 \\
Personal Health Assessment/Depression & 0.0212 \\
Nutritional State/Depression (Screening) & 0.0692 \\
Nutritional State/Depression (Assessment) & 0.0212 \\
\hline
\end{tabular}

Table 5: Common Disease Conditions among the study sample

\begin{tabular}{lcc} 
Condition & Frequency $(\mathrm{n}=\mathbf{8 6})$ & Percentage $\mathbf{1 0 0 \%}$ \\
\hline Diabetes & 2 & $2.33 \%$ \\
Hypertension & 5 & $5.81 \%$ \\
Arthritis & 4 & $4.65 \%$ \\
Incontinence & 0 & $0.00 \%$ \\
Memory Lapses & 11 & $12.79 \%$ \\
Asthma & 0 & $0.00 \%$ \\
Multiple Cormobidities & 14 & $16.28 \%$ \\
None & 28 & $32.56 \%$ \\
Liver disease & 22 & $25.58 \%$ \\
\hline
\end{tabular}

\section{DISCUSSION}

Though studies have been carried out on inmates in several prisons including the Jos Central Prison, few and far inbetween will you find such studies specifically addressing the health needs of older adult prisoners. This study had the overarching goal of establishing the prevalence of depression among older prisoners and the relationship of depression to other demographic variables. Most of the study population were male (98.64\%) with only a tiny fraction of $1.36 \%$ of female older prisoners. This is not surprising because women form a small proportion of prison population, ${ }^{6,9}$. Most of them were between the ages of $50-60$ years. Three quarters $(74.44 \%)$ of them were literates with only a quarter with no education and a small fraction who dropped out of school.

This study revealed the prevalence of depression among older adult prisoners to be $59 \%$. When compared to other studies in South-South Nigeria 37\%, South West 24.7\% and other parts of the world 28.3\%, 40\% in Brazil, $43.8 \%$ in Ethiopia and $10.4 \%$ in South Africa, ${ }^{10,11,12,13,14,15}$ it is clear that depression is higher among older adult prisoners, which could explain the difference in prevalence and implicate age as contributive factor. Though Fatoye et al, ${ }^{16}$ found depression as a correlate of emotional burden in prisoners to be higher at a figure of $85 \%$. Fatoye and colleagues discovered a high number in their sample had low education which showed a strong correlation with depression. Observational studies in India, USA and Europe report that lower education and poor economic status are associated with depression ${ }^{17}$. In our study, most of the sample (over 75\%) had formal education lowering the risk for depression. A part of the study population was awaiting trial, while others had been given shorter sentences. Majority of the sample studied $(67 \%)$ scored above the cutoff point on the Geriatric depression scale (Table 3 ). This could be explained by the fact that prison life in Nigeria denies inmates opportunities to be gainfully employed with harsh living conditions, which could be a major stressor, a view supported by Park et al ${ }^{18}$ regarding effects of employment and occupation on late life Depression. Factors such as occupational status, history of Psychiatric illness, suffering from any specific medical illness and comorbidities as well as perception of their health status were all found to be statistically significant as it relates to the development of depression. Health needs and status of older prisoners are thought to be better determinants of the limitations to activities of daily living (ADL), than the 
presence of chronic diseases, Greene et al..$^{19}$ This highlights the subjectivity in the issues of health than the real illness itself. In this study, over half, 46 (53.49\%) viewed their health condition favorably, though majority $(68 \%)$ had specific medical conditions (Fig II). This fact could be used to target diseases in prison and for planning geriatric- focused care. Liver diseases, hypertension, arthritis, memory impairments and comorbidities were found to be high in the study population (Table 5). This aligns with other findings by Greene and his colleague in 2018. In another similar study in South West Nigeria, Majekodunmi et al ${ }^{11}$ established that older prisoners with similar demographics with physical comorbidities were predictive of depression. In this study we found occupational status prior to incarceration, physical comorbidities, and older prisoner's perception of their health status as significant predictors of depression (table 4). In the context of social capital of inmates, with restrictive authority, absence of socializing outlets and institutional helplessness, health outcomes are bound to be poor. This is especially so, when health is looked at from the mental health perspective along with the major attributes of social capital, such as selfidentity, interpersonal relationships and trust. We discovered that if the significant predictors of depression which included perception of health status and engagement in occupational pursuits could be addressed in the care of older prisoners, positive outcomes are possible.

\section{CONCLUSION}

The study revealed that male gender predominate the sample of older adult prisoners with a prevalence of depression at $59 \%$ among them. The significant predictors of depression include occupational status prior to incarceration, perception of their health status and medical comorbidities of the prisoners.

\section{Conflict of Interest}

None declared

\section{REFERENCES}

1. Nacher M, Ayhan G, Arnal R, Basurka C, Huber, F. High prevalence rates of multiple Psychiatry condition among inmates at French Guiana's correctional facility: Diagnostic and demographic factors association with violent offending and previous Incarceration. BMC Psychiatry, 2018; 18(159).

2. Baidawi S, Turner S. Older prisoners: A challenge for Australian corrections. Trends and Issues in Crime and Justice, 2011.462.
3. Baidawi S, Trotter C. Psychological distress among older prisoners. A literature review Journal of Forensic and social science, 2015; (5): 234-257.

4. Walmsley R. World prison population list. Institute for criminal policy Research. 2018.12 $12^{\text {th }}$ Edition.

5. De Viggiani N. Surviving Prison: Exploring prison social life as a determinant of health. International Journal of Prisoner health, 2006;2(2):71-89.

6. Crawley E, Sparks R. "Is there life after imprisonment? How elderly men talk about imprisonment and Release" Criminology and Criminal Justice, 2006; 6(1):

7. Obioha E. Challenges and reforms in the Nigerian prison system. Journal of social sciences, 2011;27:95-109.

8. Robertson S. 'Not living life in too much of an excess': laymen understanding health and well-being. Health, 2006; 10:175-89. 10.1177/1363459306061787.

9. Udofia O. Mental illness and crime in Southeastern Nigeria. Nig. J. Psych, 1997; 1: 209-216.

10. Nwaopara U, Stanley P. Prevalence of Depression in Port Harcourt Prison. Journal of Psychiatry, 2015;18: 340.

11. Majekodunm, OE, Obadeji A, Oluwole OL, Oyelami O. Depression and associated physical co-morbidities in elderly prisoners. International Journal of mental health, 2017;46(4):

12. Di-Lorito C, Vollm B, Dening T. Psychiatric disorders among older prisoners: a systematic review and comparison study against older people in the community. Aging and mental health, 2016; 22(1):

13. Andreoli SB, Dos Santos, MM Quintana, MI et al. "Prevalence of mental disorders among prisoners in the state of Sao Paulo, Brazil," 2014; 9(2): e88836.

14. Beyen, TK, Dadi, AF, Dachew, BA, Muluneh, NY, Bisetegn TA. "More than eight in every nineteen inmates were living with depression at prisons of Northwest Amhara Regional State, Ethiopia, across sectional study design," BMC Psychiatry, 2017; 17 (31): 1-9.

15. Naidoo S, Mkize DL. Prevalence of mental disorders in a prison population in Durban, South Africa. South African Journal of Psychiatry, 2012; 15(1):30-35.

16. Fatoye FO, Fatoye GK, Oyebanji AO, Ogunro AS. Psychological characteristics as correlates of emotional burden in Incarcerated offenders in Nigeria. East African Medical Journal, 2006; 83: 545-552.

17. Brown CR, Hambleton IR, Sobers-Grannum N, Hercules SM, Unwin N. Social determinants of depression and suicidal behaviour in the Caribbean: a systematic review. BMC Public Health, 2017; 17:577.

18. Park H, Hwangbo Y, Lee Y, Jan E, Han W. Employment and occupational effects on late life depressive symptoms among older Koreans. Annals of occupational and Environmental Medicine, 2016;28(22):

19. Greene M, Ahalt C, Metzger L, Stijacic-Cenzer I, Williams B. Older adults in Jail. High rates and early onset of Geriatric condition. Health Justice, 2018; 6(3): 